\title{
Partial Molar Volumes of 15-Crown-5 Ether in Mixtures of $N, N$-Dimethylformamide with Water
}

\author{
Magdalena Tyczyńska • Małgorzata Jóźwiak
}

Received: 1 July 2013/Accepted: 22 October 2013/Published online: 8 February 2014

(C) The Author(s) 2014. This article is published with open access at Springerlink.com

\begin{abstract}
The density of 15-crown-5 ether (15C5) solutions in the mixtures of $N, N$ dimethylformamide (DMF) and water $\left(\mathrm{H}_{2} \mathrm{O}\right)$ was measured within the temperature range 293.15-308.15 K using an Anton Paar oscillatory U-tube densimeter. The results were used to calculate the apparent molar volumes $\left(V_{\Phi}\right)$ of $15 \mathrm{C} 5$ in the mixtures of DMF $+\mathrm{H}_{2} \mathrm{O}$ over the whole concentration range. Using the apparent molar volumes and Redlich and Mayer equation, the standard partial molar volumes of 15-crown-5 were calculated at infinite dilution $\left(V_{\mathrm{m}}^{\circ}\right)$. The limiting apparent molar expansibilities $(\alpha)$ were also calculated. The data are discussed from the point of view of the effect of concentration changes on interactions in solution.
\end{abstract}

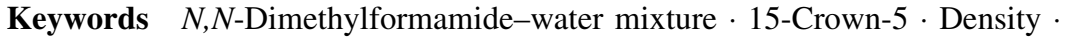
Partial molar volume $\cdot$ Hydrophobic hydration

\section{Introduction}

Studies of the properties of solutions connected with their density within a wide range of concentration and temperatures are a valuable source of information. The volumetric functions and the temperature coefficient of expansion make it possible to know not only the physical properties of the solute and solvent under investigation, but they can also be used to verify changes occurring in the solution structure brought about by intermolecular interactions [1-7].

In our measurements solutions of $15 \mathrm{C} 5$ in $\mathrm{DMF}+\mathrm{H}_{2} \mathrm{O}$ mixtures were used. The special properties of water can be changed under the influence of a substance dissolved in it. Depending on the hydrophobic-hydrophilic properties of the solute, the three-dimensional network of hydrogen bonds can be reinforced or weakened, which may show itself

M. Tyczyńska · M. Jóźwiak (凹)

Department of Physical Chemistry, University of Lodz, Pomorska 165, 90-236 Lodz, Poland

e-mail: mjozwiak@uni.lodz.pl 
in changes in the density of aqueous solutions (molar volume) and changes in chemical potential [8].

The investigation of changes in the interactions among the components of mixed solvent and solute with hydrophobic-hydrophilic properties requires one to choose an organic solvent that does not specifically react with water. This will allow one to observe changes in the interactions among the mixture components and solute, brought about by the process of preferential solvation including the hydrophobic hydration of the solute. This requirement is met by $N, N$-dimethylformamide (DMF). Its molecules have groups with hydrophilic and hydrophobic properties that are almost mutually compensated, which makes them a convenient object for investigations in a mixture with water [9]. DMF is used as model substance for investigation the interactions of small biological molecules serving as a model compound for protein [10]. The amide group can serve as a model of the peptide bond, and interactions between hydroxyl and amide groups play an important role in the solvation of peptides in aqueous solutions [11].

Crown ethers constitute a very interesting class of compounds characterized by hydrophilic-hydrophobic properties resulting from their structure. Therefore they are capable of selective complexation of ions and small organic molecules; thus, for example, they are used to make ion selective electrodes [12].

One can find many studies more or less successfully describing the effect of crown ether molecules on the interactions in mixed aqueous-organic and organic-organic solvents. Such studies have been carried out by means of various experimental techniques [13-19]. In the literature, there are few papers on the volumetric properties of crown ethers in water or in mixtures of water with an organic solvent $[16,20]$.

In this paper we present the effect of the mixed solvent composition and temperature on the volumetric properties of the system $15 \mathrm{C} 5+\mathrm{DMF}+\mathrm{H}_{2} \mathrm{O}$. The data are compared with analogous results previously obtained for the solutions of urea (a hydrophilic compound) in the mixtures of DMF and water [21].

\section{Experimental and Method}

\subsection{Materials}

15-crown-5 (Aldrich, w $=0.98$ ) was used as received. DMF (Aldrich, mass fraction $=0.99$ ) was purified and dried according to the procedures described in the literature $[22,23]$ and distilled under vacuum. Water content, determined by the Karl Fisher method, was lower than $0.01 \%$. To prepare aqueous solutions, triple-distilled and degassed water was used.

\subsection{Measurements}

The densities of the 15C5 solutions within the whole concentration range of mixed solvent, at temperatures $T / \mathrm{K}=293.15,298.15,303.15$ and 308.15, were measured with the use of an Anton Paar densimeter, model DMA 5000 with an oscillatory U-tube, whose uncertainty of density and temperature measurements are $\pm 5 \times 10^{-3} \mathrm{~kg} \cdot \mathrm{m}^{-3}$ and $\pm 0.01 \mathrm{~K}$, respectively, and the temperature stability is $\pm 0.005 \mathrm{~K}$. The densimeter was calibrated with the use of pure water. The obtained value of water density equal to $997.046 \mathrm{~kg} \cdot \mathrm{m}^{-3}$ at a temperature of $298.15 \mathrm{~K}$ is in agreement with the literature data [24]. The mixed solvent DMF $+\mathrm{H}_{2} \mathrm{O}$ and solutions of 15-crown-5 in DMF $+\mathrm{H}_{2} \mathrm{O}$ were prepared by weight using 
Table 1 Experimental density of $N, N$-dimethylformamide and literature data

\begin{tabular}{lllll}
\hline Substance & $\rho \times 10^{3}\left(\mathrm{~kg} \cdot \mathrm{m}^{-3}\right)$ & & \\
\cline { 2 - 5 } & $T=293.15 \mathrm{~K}$ & $T=298.15 \mathrm{~K}$ & $T=303.15 \mathrm{~K}$ & $T=308.15 \mathrm{~K}$ \\
\hline DMF & 0.948737 & 0.943971 & 0.939196 & 0.934420 \\
& $0.94939^{\mathrm{a}}$ & $0.94460^{\mathrm{a}}$ & $0.93983^{\mathrm{a}}$ & $0.93505^{\mathrm{a}}$ \\
& $0.95045^{\mathrm{b}}$ & $0.94559^{\mathrm{b}}$ & $0.94069^{\mathrm{b}}$ & $0.93561^{\mathrm{b}}$ \\
& $0.948051^{\mathrm{c}}$ & $0.942915^{\mathrm{c}}$ & $0.938876^{\mathrm{c}}$ & $0.933964^{\mathrm{c}}$ \\
& $0.94917^{\mathrm{d}}$ & $0.944^{\mathrm{e}}$ & $0.9386^{\mathrm{h}}$ & $0.9344^{\mathrm{h}}$ \\
& $0.94381^{\mathrm{f}}$ & & \\
& & $0.94403^{\mathrm{g}}$ & & \\
\hline
\end{tabular}

${ }^{a}$ Berna-García et al. [25]

${ }^{b}$ Marchetti et al. [26]

c Sharlin et al. [27]

d Tôrres et al. [28]

e Bakshi et al. [29]

${ }^{\mathrm{f}}$ Bendová et al. [30]

g Tong-Chun et al. [31]

${ }^{h}$ Akhtar et al. [32]

electronic balances with an accuracy of $\pm 1 \times 10^{-2}$ and $\pm 1 \times 10^{-5} \mathrm{~g}$, respectively. The values of experimental densities of pure $N, N$-dimethylformamide are compared with literature data and collected in Table 1 . The values of the solution densities obtained as a function of molality, $m$ ( $m$ expressed as moles of 15-crown-5 per kilogram of solvent) at investigated temperatures, are presented in Table 2.

\section{Results and Discussion}

Using the density values of 15-crown-5 (15C5) in DMF $+\mathrm{H}_{2} \mathrm{O}$ mixtures (Table 2), the apparent molar volume of $15 \mathrm{C} 5$ in $\mathrm{DMF}+\mathrm{H}_{2} \mathrm{O}$ mixtures was calculated using Eq. 1:

$$
V_{\Phi}=M / \rho-1000 \cdot\left(\rho-\rho_{\mathrm{o}}\right) / m \cdot \rho \cdot \rho_{\mathrm{o}}
$$

where $M$ is a molar mass of $15 \mathrm{C} 5, \rho_{\mathrm{o}}$ is the density of DMF $+\mathrm{H}_{2} \mathrm{O}$ mixtures, $\rho$ indicates the density of the $15 \mathrm{C} 5+\mathrm{DMF}+\mathrm{H}_{2} \mathrm{O}$ system and $m$ is the concentration of $15 \mathrm{C} 5$ in moles per kilogram of solvent. The dependence of $V_{\Phi}$ on the solute molality, $V_{\Phi}=f(m)$, can be described by Eq. 2:

$$
V_{\Phi}=V_{\Phi}^{\circ}+b_{\mathrm{V}} m
$$

Equation 2 is a special case of the dependence proposed by Redlich and Meyer [33]:

$$
V_{\Phi}=V_{\Phi}^{\circ}+S_{\mathrm{V}} \sqrt{m}+b_{\mathrm{V}} m
$$

where $S_{\mathrm{V}}$ and $b_{\mathrm{V}}$ are empirical parameters. The parameter $S_{\mathrm{V}}$ is connected with the interaction of ions in solution, which can be calculated from Debye-Hückel's limiting law. For solutions of nonelectrolytes, $S_{\mathrm{V}}=0$ [34]. The parameter $b_{\mathrm{V}}$ provides information about the character of interactions of solute molecules between themselves. 
Table 2 Experimental densities, $\rho$, of 15-crown-5 in the DMF $+\mathrm{H}_{2} \mathrm{O}$ mixtures at temperatures $T=(293.15,298.15,303.15$ and 308.15$) \mathrm{K}$

\begin{tabular}{|c|c|c|c|c|c|}
\hline \multirow[t]{2}{*}{$x_{2}$} & \multirow[t]{2}{*}{$m\left(\mathrm{~mol} \cdot \mathrm{kg}^{-1}\right)$} & \multicolumn{4}{|c|}{$\rho \times 10^{3}\left(\mathrm{~kg} \cdot \mathrm{m}^{-3}\right)$} \\
\hline & & $T=293.15 \mathrm{~K}$ & $T=298.15 \mathrm{~K}$ & $T=303.15 \mathrm{~K}$ & $T=308.15 \mathrm{~K}$ \\
\hline \multirow[t]{9}{*}{0.00} & 0 & 0.948737 & 0.943971 & 0.939196 & 0.934420 \\
\hline & 0.02548 & 0.949612 & 0.944847 & 0.940074 & 0.935300 \\
\hline & 0.05941 & 0.950756 & 0.945992 & 0.941221 & 0.936447 \\
\hline & 0.08622 & 0.951640 & 0.946877 & 0.942114 & 0.937343 \\
\hline & 0.11692 & 0.952642 & 0.947884 & 0.943125 & 0.938359 \\
\hline & 0.13341 & 0.953166 & 0.948402 & 0.943644 & 0.938876 \\
\hline & 0.17510 & 0.954477 & 0.949715 & 0.944959 & 0.940197 \\
\hline & 0.20937 & 0.955535 & 0.950789 & 0.946034 & 0.941275 \\
\hline & 0.24408 & 0.956576 & 0.951832 & 0.947081 & 0.942326 \\
\hline \multirow[t]{9}{*}{0.10} & 0 & 0.953731 & 0.948879 & 0.944216 & 0.939439 \\
\hline & 0.03367 & 0.954840 & 0.949990 & 0.945328 & 0.940554 \\
\hline & 0.06351 & 0.955807 & 0.950958 & 0.946296 & 0.941523 \\
\hline & 0.09159 & 0.956705 & 0.951856 & 0.947199 & 0.942428 \\
\hline & 0.12396 & 0.957723 & 0.952879 & 0.948218 & 0.943453 \\
\hline & 0.15189 & 0.958575 & 0.953736 & 0.949088 & 0.944310 \\
\hline & 0.18502 & 0.959590 & 0.954751 & 0.950095 & 0.945334 \\
\hline & 0.20868 & 0.960304 & 0.955451 & 0.950810 & 0.946049 \\
\hline & 0.25199 & 0.961562 & 0.956728 & 0.952086 & 0.947332 \\
\hline \multirow[t]{9}{*}{0.20} & 0 & 0.959310 & 0.954573 & 0.949823 & 0.945045 \\
\hline & 0.04255 & 0.960655 & 0.955919 & 0.951171 & 0.946398 \\
\hline & 0.07195 & 0.961569 & 0.956833 & 0.952086 & 0.947314 \\
\hline & 0.09842 & 0.962382 & 0.957646 & 0.952903 & 0.948136 \\
\hline & 0.12857 & 0.963288 & 0.958561 & 0.953820 & 0.949060 \\
\hline & 0.15401 & 0.964054 & 0.959321 & 0.954584 & 0.949819 \\
\hline & 0.18505 & 0.964960 & 0.960245 & 0.955506 & 0.950752 \\
\hline & 0.21101 & 0.965727 & 0.961002 & 0.956267 & 0.951517 \\
\hline & 0.25734 & 0.967045 & 0.962328 & 0.957596 & 0.952839 \\
\hline \multirow[t]{9}{*}{0.30} & 0 & 0.965705 & 0.960992 & 0.956253 & 0.951493 \\
\hline & 0.02471 & 0.966441 & 0.961730 & 0.956994 & 0.952236 \\
\hline & 0.05485 & 0.967328 & 0.962619 & 0.957884 & 0.953130 \\
\hline & 0.08073 & 0.968082 & 0.963374 & 0.958637 & 0.953883 \\
\hline & 0.10921 & 0.968901 & 0.964195 & 0.959466 & 0.954715 \\
\hline & 0.13379 & 0.969599 & 0.964897 & 0.960160 & 0.955410 \\
\hline & 0.16111 & 0.970369 & 0.965665 & 0.960939 & 0.956192 \\
\hline & 0.17732 & 0.970821 & 0.966119 & 0.961394 & 0.956647 \\
\hline & 0.21842 & 0.971953 & 0.967254 & 0.962534 & 0.957787 \\
\hline
\end{tabular}


Table 2 continued

\begin{tabular}{|c|c|c|c|c|c|}
\hline \multirow[t]{2}{*}{$x_{2}$} & \multirow[t]{2}{*}{$m\left(\mathrm{~mol} \cdot \mathrm{kg}^{-1}\right)$} & \multicolumn{4}{|c|}{$\rho \times 10^{3}\left(\mathrm{~kg} \cdot \mathrm{m}^{-3}\right)$} \\
\hline & & $T=293.15 \mathrm{~K}$ & $T=298.15 \mathrm{~K}$ & $T=303.15 \mathrm{~K}$ & $T=308.15 \mathrm{~K}$ \\
\hline \multirow[t]{9}{*}{0.40} & 0 & 0.972987 & 0.968296 & 0.963577 & 0.958796 \\
\hline & 0.02690 & 0.973758 & 0.969067 & 0.964349 & 0.959571 \\
\hline & 0.05893 & 0.974663 & 0.969974 & 0.965259 & 0.960484 \\
\hline & 0.07837 & 0.975204 & 0.970517 & 0.965806 & 0.961031 \\
\hline & 0.11204 & 0.976138 & 0.971452 & 0.966740 & 0.961967 \\
\hline & 0.13346 & 0.976713 & 0.972038 & 0.967327 & 0.962556 \\
\hline & 0.16708 & 0.977630 & 0.972948 & 0.968239 & 0.963471 \\
\hline & 0.19964 & 0.978498 & 0.973818 & 0.969110 & 0.964344 \\
\hline & 0.23028 & 0.979305 & 0.974627 & 0.969920 & 0.965157 \\
\hline \multirow[t]{9}{*}{0.50} & 0 & 0.980849 & 0.976200 & 0.971517 & 0.966802 \\
\hline & 0.02234 & 0.981473 & 0.976823 & 0.972141 & 0.967426 \\
\hline & 0.05427 & 0.982354 & 0.977704 & 0.973025 & 0.968309 \\
\hline & 0.07937 & 0.983037 & 0.978387 & 0.973710 & 0.968992 \\
\hline & 0.10775 & 0.983803 & 0.979151 & 0.974479 & 0.969758 \\
\hline & 0.12484 & 0.984258 & 0.979608 & 0.974936 & 0.970217 \\
\hline & 0.16227 & 0.985245 & 0.980597 & 0.975928 & 0.971207 \\
\hline & 0.19826 & 0.986181 & 0.981530 & 0.976867 & 0.972146 \\
\hline & 0.22877 & 0.986960 & 0.982314 & 0.977652 & 0.972930 \\
\hline \multirow[t]{9}{*}{0.60} & 0 & 0.988582 & 0.984016 & 0.979419 & 0.974785 \\
\hline & 0.02030 & 0.989155 & 0.984587 & 0.979990 & 0.975354 \\
\hline & 0.03362 & 0.989529 & 0.984960 & 0.980362 & 0.975726 \\
\hline & 0.06490 & 0.990396 & 0.985826 & 0.981225 & 0.976588 \\
\hline & 0.09303 & 0.991169 & 0.986597 & 0.981997 & 0.977360 \\
\hline & 0.12367 & 0.992000 & 0.987427 & 0.982827 & 0.978187 \\
\hline & 0.15369 & 0.992802 & 0.988226 & 0.983625 & 0.978984 \\
\hline & 0.18395 & 0.993600 & 0.989023 & 0.984420 & 0.979780 \\
\hline & 0.25543 & 0.995445 & 0.990865 & 0.986260 & 0.981619 \\
\hline \multirow[t]{9}{*}{0.70} & 0 & 0.995521 & 0.991167 & 0.986768 & 0.982319 \\
\hline & 0.03136 & 0.996464 & 0.992101 & 0.987695 & 0.983239 \\
\hline & 0.06435 & 0.997443 & 0.993070 & 0.988659 & 0.984194 \\
\hline & 0.09125 & 0.998224 & 0.993844 & 0.989431 & 0.984956 \\
\hline & 0.11435 & 0.998893 & 0.994508 & 0.990088 & 0.985616 \\
\hline & 0.15157 & 0.999956 & 0.995565 & 0.991137 & 0.986646 \\
\hline & 0.18098 & 1.000785 & 0.996387 & 0.991953 & 0.987424 \\
\hline & 0.20196 & 1.001369 & 0.996967 & 0.992529 & 0.988026 \\
\hline & 0.23981 & 1.002417 & 0.998008 & 0.993562 & 0.989070 \\
\hline
\end{tabular}


Table 2 continued

\begin{tabular}{|c|c|c|c|c|c|}
\hline \multirow[t]{2}{*}{$x_{2}$} & \multirow[t]{2}{*}{$m\left(\mathrm{~mol} \cdot \mathrm{kg}^{-1}\right)$} & \multicolumn{4}{|c|}{$\rho \times 10^{3}\left(\mathrm{~kg} \cdot \mathrm{m}^{-3}\right)$} \\
\hline & & $T=293.15 \mathrm{~K}$ & $T=298.15 \mathrm{~K}$ & $T=303.15 \mathrm{~K}$ & $T=308.15 \mathrm{~K}$ \\
\hline \multirow[t]{9}{*}{0.80} & 0 & 0.999822 & 0.995938 & 0.991999 & 0.987998 \\
\hline & 0.03182 & 1.000884 & 0.996986 & 0.993035 & 0.989021 \\
\hline & 0.06761 & 1.002061 & 0.998150 & 0.994180 & 0.990158 \\
\hline & 0.10137 & 1.003158 & 0.999234 & 0.995264 & 0.991212 \\
\hline & 0.13026 & 1.004090 & 1.000146 & 0.996151 & 0.992096 \\
\hline & 0.15750 & 1.004958 & 1.001001 & 0.996994 & 0.992930 \\
\hline & 0.19474 & 1.006118 & 1.002143 & 0.998121 & 0.994039 \\
\hline & 0.20937 & 1.006572 & 1.002591 & 0.998563 & 0.994478 \\
\hline & 0.26742 & 1.008344 & 1.004339 & 1.000287 & 0.996181 \\
\hline \multirow[t]{9}{*}{0.90} & 0 & 0.999747 & 0.996896 & 0.993931 & 0.990857 \\
\hline & 0.02425 & 1.000667 & 0.997792 & 0.994803 & 0.991718 \\
\hline & 0.06077 & 1.002037 & 0.999125 & 0.996102 & 0.993000 \\
\hline & 0.10132 & 1.003533 & 1.000583 & 0.997525 & 0.994401 \\
\hline & 0.11740 & 1.004122 & 1.001160 & 0.998083 & 0.994952 \\
\hline & 0.13681 & 1.004826 & 1.001846 & 0.998748 & 0.995613 \\
\hline & 0.17294 & 1.006122 & 1.003106 & 0.999979 & 0.996827 \\
\hline & 0.20232 & 1.007166 & 1.004121 & 1.000967 & 0.997804 \\
\hline & 0.23732 & 1.008391 & 1.005317 & 1.002131 & 0.998952 \\
\hline \multirow[t]{9}{*}{0.92} & 0 & 0.999213 & 0.996655 & 0.993967 & 0.991148 \\
\hline & 0.03136 & 1.000408 & 0.997816 & 0.995106 & 0.992268 \\
\hline & 0.06265 & 1.001589 & 0.998962 & 0.996231 & 0.993374 \\
\hline & 0.09774 & 1.002895 & 1.000233 & 0.997477 & 0.994599 \\
\hline & 0.12799 & 1.004011 & 1.001315 & 0.998539 & 0.995644 \\
\hline & 0.15895 & 1.005139 & 1.002411 & 0.999614 & 0.996700 \\
\hline & 0.19205 & 1.006334 & 1.003571 & 1.000751 & 0.997819 \\
\hline & 0.21136 & 1.007023 & 1.004239 & 1.001408 & 0.998464 \\
\hline & 0.26014 & 1.008749 & 1.005912 & 1.003051 & 1.000078 \\
\hline \multirow[t]{9}{*}{0.94} & 0 & 0.998613 & 0.996383 & 0.993997 & 0.991465 \\
\hline & 0.03717 & 1.000020 & 0.997759 & 0.995345 & 0.992788 \\
\hline & 0.06953 & 1.001232 & 0.998944 & 0.996502 & 0.993923 \\
\hline & 0.09583 & 1.002213 & 0.999904 & 0.997433 & 0.994832 \\
\hline & 0.13217 & 1.003545 & 1.001207 & 0.998721 & 0.996094 \\
\hline & 0.16474 & 1.004731 & 1.002368 & 0.999851 & 0.997212 \\
\hline & 0.20262 & 1.006084 & 1.003694 & 1.001159 & 0.998491 \\
\hline & 0.22400 & 1.006831 & 1.004423 & 1.001871 & 0.999187 \\
\hline & 0.27371 & 1.008583 & 1.006135 & 1.003547 & 1.000829 \\
\hline
\end{tabular}


Table 2 continued

\begin{tabular}{|c|c|c|c|c|c|}
\hline \multirow[t]{2}{*}{$x_{2}$} & \multirow[t]{2}{*}{$m\left(\mathrm{~mol} \cdot \mathrm{kg}^{-1}\right)$} & \multicolumn{4}{|c|}{$\rho \times 10^{3}\left(\mathrm{~kg} \cdot \mathrm{m}^{-3}\right)$} \\
\hline & & $T=293.15 \mathrm{~K}$ & $T=298.15 \mathrm{~K}$ & $T=303.15 \mathrm{~K}$ & $T=308.15 \mathrm{~K}$ \\
\hline \multirow[t]{9}{*}{0.96} & 0 & 0.998064 & 0.996186 & 0.994128 & 0.991899 \\
\hline & 0.02961 & 0.999179 & 0.997277 & 0.995195 & 0.992944 \\
\hline & 0.06577 & 1.000529 & 0.998597 & 0.996484 & 0.994206 \\
\hline & 0.09853 & 1.001742 & 0.999775 & 0.997638 & 0.995337 \\
\hline & 0.12369 & 1.002660 & 1.000674 & 0.998517 & 0.996199 \\
\hline & 0.15178 & 1.003682 & 1.001671 & 0.999488 & 0.997147 \\
\hline & 0.18196 & 1.004770 & 1.002731 & 1.000525 & 0.998162 \\
\hline & 0.21265 & 1.005857 & 1.003794 & 1.001564 & 0.999177 \\
\hline & 0.25315 & 1.007279 & 1.005182 & 1.002920 & 1.000502 \\
\hline \multirow[t]{9}{*}{0.98} & 0 & 0.997773 & 0.996269 & 0.994553 & 0.992644 \\
\hline & 0.02909 & 0.998855 & 0.997327 & 0.995588 & 0.993659 \\
\hline & 0.06203 & 1.000069 & 0.998512 & 0.996751 & 0.994798 \\
\hline & 0.09171 & 1.001153 & 0.999570 & 0.997786 & 0.995811 \\
\hline & 0.12209 & 1.002250 & 1.000647 & 0.998833 & 0.996846 \\
\hline & 0.15501 & 1.003428 & 1.001796 & 0.999969 & 0.997943 \\
\hline & 0.18354 & 1.004440 & 1.002784 & 1.000930 & 0.998902 \\
\hline & 0.20860 & 1.005323 & 1.003649 & 1.001774 & 0.999726 \\
\hline & 0.24953 & 1.006746 & 1.005039 & 1.003135 & 1.001057 \\
\hline \multirow[t]{9}{*}{1.00} & 0 & 0.998199 & 0.997043 & 0.995649 & 0.994041 \\
\hline & 0.02470 & 0.999077 & 0.997898 & 0.996488 & 0.994859 \\
\hline & 0.06100 & 1.000348 & 0.999145 & 0.997711 & 0.996065 \\
\hline & 0.09177 & 1.001429 & 1.000189 & 0.998745 & 0.997078 \\
\hline & 0.11536 & 1.002244 & 1.000985 & 0.999524 & 0.997845 \\
\hline & 0.13029 & 1.002753 & 1.001488 & 1.000020 & 0.998329 \\
\hline & 0.17530 & 1.004282 & 1.002977 & 1.001491 & 0.999777 \\
\hline & 0.20216 & 1.005193 & 1.003866 & 1.002358 & 1.000628 \\
\hline & 0.23731 & 1.006360 & 1.005023 & 1.003489 & 1.001745 \\
\hline
\end{tabular}

$x_{2}$ is the mole fraction of water in the mixture

The values of $b_{\mathrm{V}}$ obtained as a function of the molar fraction of water are listed in Table 3. Considering the considerable standard deviations of the values of $b_{\mathrm{V}}$, these values will be discussed in qualitative terms. Up to $x_{2}=0.9$ the values of $b_{\mathrm{V}}$ are positive. In the mixture with high water content, i.e. $x_{2}>0.9$, these values are negative. The negative sign of coefficient $b_{\mathrm{V}}$ reflects the hydrophobic properties of $15 \mathrm{C} 5$ molecules [35, 36]. As can be seen the values of $b_{\mathrm{V}}$ decrease with increasing water content in the mixtures. This means that the interactions between the molecules of solute are becoming stronger [37, 38]. This is consistent with hydrophobic hydration of $15 \mathrm{C} 5$ molecules in aqueous medium and their enclosure in clathrate-like water structures.

For urea [21] the decreasing values of $V_{\Phi}$ with increasing urea content in the mixture testify to the existence of increasing short range attractions between urea molecules [37]. In the case of the DMF $+\mathrm{H}_{2} \mathrm{O}+$ urea system, the values of $b_{\mathrm{V}}$ are negative but they 
Table 3 Coefficient $b_{\mathrm{V}}$ of Eq. 2

\begin{tabular}{lrrrr}
\hline$x_{2}$ & \multicolumn{3}{l}{$b_{\mathrm{V}} \times 10^{6}\left(\mathrm{~m}^{3} \cdot \mathrm{kg} \cdot \mathrm{mol}^{-2}\right)$} & \\
\cline { 2 - 5 } & $T=293.15 \mathrm{~K}$ & $T=298.15 \mathrm{~K}$ & $T=303.15 \mathrm{~K}$ & $T=308.15 \mathrm{~K}$ \\
\hline 0.00 & $4.71 \pm 0.10$ & $4.48 \pm 0.24$ & $4.46 \pm 0.22$ & $4.32 \pm 0.30$ \\
0.10 & $2.99 \pm 0.18$ & $3.04 \pm 0.14$ & $2.69 \pm 0.13$ & $2.71 \pm 0.18$ \\
0.20 & $1.81 \pm 0.15$ & $1.43 \pm 0.07$ & $1.30 \pm 0.07$ & $1.34 \pm 0.22$ \\
0.30 & $0.76 \pm 0.03$ & $0.82 \pm 0.04$ & $0.88 \pm 0.23$ & $1.06 \pm 0.24$ \\
0.40 & $0.79 \pm 0.18$ & $0.56 \pm 0.04$ & $0.61 \pm 0.09$ & $0.75 \pm 0.06$ \\
0.50 & $0.80 \pm 0.05$ & $0.59 \pm 0.04$ & $0.35 \pm 0.08$ & $0.47 \pm 0.05$ \\
0.60 & $0.64 \pm 0.06$ & $0.52 \pm 0.09$ & $0.57 \pm 0.11$ & $0.36 \pm 0.12$ \\
0.70 & $0.91 \pm 0.14$ & $0.62 \pm 0.16$ & $0.68 \pm 0.10$ & $0.85 \pm 0.51$ \\
0.80 & $0.42 \pm 0.12$ & $0.68 \pm 0.10$ & $0.96 \pm 0.28$ & $1.06 \pm 0.13$ \\
0.90 & $0.51 \pm 0.04$ & $0.41 \pm 0.09$ & $0.34 \pm 0.08$ & $0.27 \pm 0.04$ \\
0.92 & $-0.25 \pm 0.04$ & $-0.17 \pm 0.02$ & $-0.19 \pm 0.02$ & $-0.19 \pm 0.02$ \\
0.94 & $-0.42 \pm 0.18$ & $-0.51 \pm 0.20$ & $-0.72 \pm 0.19$ & $-0.68 \pm 0.25$ \\
0.96 & $-0.97 \pm 0.15$ & $-0.60 \pm 0.08$ & $-0.55 \pm 0.03$ & $-0.38 \pm 0.08$ \\
0.98 & $-0.90 \pm 0.04$ & $-0.96 \pm 0.06$ & $-0.86 \pm 0.12$ & $-0.92 \pm 0.12$ \\
1.00 & $-1.71 \pm 0.29$ & $-1.65 \pm 0.15$ & $-1.59 \pm 0.14$ & $-1.44 \pm 0.10$ \\
\hline
\end{tabular}

\pm is the standard deviation

become less negative with increasing water content in the mixtures, which indicates hydrophilic properties of urea and that the solute-solute interactions have become weaker [21].

The values of the standard partial molar volume, $V_{\mathrm{m}}^{\circ}\left(V_{\Phi}^{\circ}=V_{\mathrm{m}}^{\circ}\right)$, of $15 \mathrm{C} 5$ obtained by the extrapolation of $V_{\Phi}$ data are presented in Table 4 and in Fig. 1 as a function of the molar fraction of water. The same figure also shows the values of the standard partial molar volume of urea with hydrophilic properties within the same range of concentrations and temperatures that were published in our previous paper [21]. As is seen in Fig. 1, for 15C5 showing hydrophobic properties, the values of the standard partial molar volume in the mixture of DMF and water are considerably higher than those of urea. This difference also directly results from the considerable differences in the molecular sizes of the compounds. Analyzing the dependence $V_{\mathrm{m}}^{\circ}=f\left(x_{2}\right)$ for $15 \mathrm{C} 5$, we observe an increase in the partial molar volume with increasing water content in the mixtures up to $x_{2} \approx 0.4$. This is probably due to the interactions between the polar groups of DMF and water. In a solution with low water content, the interactions between DMF and water molecules dominate. Some authors [11, 42-50] proposed the possibility of clathrate or complex formation $\left(\mathrm{DMF} \bullet\left(\mathrm{H}_{2} \mathrm{O}\right)_{n}, n=1-4\right)$. This would be the reason that the molecules of $15 \mathrm{C} 5$ are mainly solvated by the organic co-solvent.

The ordering of the mixed solvent structure and the presence of $15 \mathrm{C} 5$ molecules solvated by DMF most probably cause an increase in the values of $V_{\mathrm{m}}^{\circ}$ within the concentration range from $x_{2}=0$ to 0.4 . Further increase in the water content in the mixture probably causes the organic solvent molecules to be replaced by water molecules in the solvation shell. Taking into account the fact that the addition of water, which is a polar molecule, is a highly disadvantageous process, it may be expected that the system will tend to minimize the disadvantageous interactions between solute and water molecules. As a 
Table 4 Partial molar volume of 15 -crown-5, $V_{m}^{\circ}$, in the DMF $+\mathrm{H}_{2} \mathrm{O}$ mixtures

\begin{tabular}{|c|c|c|c|c|}
\hline \multirow[t]{2}{*}{$x_{2}$} & \multicolumn{4}{|c|}{$V_{\mathrm{m}}^{\circ} \times 10^{6}\left(\mathrm{~m}^{3} \cdot \mathrm{mol}^{-1}\right)$} \\
\hline & $T=293.15 \mathrm{~K}$ & $T=298.15 \mathrm{~K}$ & $T=303.15 \mathrm{~K}$ & $T=308.15 \mathrm{~K}$ \\
\hline 0.00 & $193.72 \pm 0.01$ & $194.49 \pm 0.04$ & $195.16 \pm 0.03$ & $195.90 \pm 0.04$ \\
\hline 0.10 & $194.39 \pm 0.03$ & $195.13 \pm 0.02$ & $195.90 \pm 0.20$ & $196.63 \pm 0.09$ \\
\hline 0.20 & $194.90 \pm 0.02$ & $195.70 \pm 0.01$ & $196.45 \pm 0.01$ & $197.13 \pm 0.04$ \\
\hline 0.30 & $195.97 \pm 0.01$ & $196.70 \pm 0.01$ & $197.42 \pm 0.03$ & $198.14 \pm 0.03$ \\
\hline 0.40 & $195.96 \pm 0.03$ & $196.73 \pm 0.01$ & $197.47 \pm 0.01$ & $198.19 \pm 0.01$ \\
\hline 0.50 & $195.39 \pm 0.01$ & $196.23 \pm 0.01$ & $196.97 \pm 0.01$ & $197.80 \pm 0.01$ \\
\hline 0.60 & $193.79 \pm 0.01$ & $194.64 \pm 0.01$ & $195.44 \pm 0.01$ & $196.31 \pm 0.02$ \\
\hline 0.70 & $190.72 \pm 0.02$ & $191.74 \pm 0.02$ & $192.65 \pm 0.02$ & $193.64 \pm 0.08$ \\
\hline 0.80 & $186.70 \pm 0.20$ & $187.71 \pm 0.02$ & $188.71 \pm 0.04$ & $189.75 \pm 0.02$ \\
\hline 0.90 & $182.18 \pm 0.01$ & $183.59 \pm 0.01$ & $185.02 \pm 0.01$ & $185.96 \pm 0.01$ \\
\hline 0.92 & $182.05 \pm 0.01$ & $183.51 \pm 0.01$ & $184.62 \pm 0.01$ & $185.66 \pm 0.01$ \\
\hline 0.94 & $182.33 \pm 0.03$ & $183.50 \pm 0.03$ & $184.68 \pm 0.03$ & $185.76 \pm 0.04$ \\
\hline 0.96 & $182.67 \pm 0.02$ & $183.78 \pm 0.01$ & $184.91 \pm 0.01$ & $185.99 \pm 0.01$ \\
\hline 0.98 & $183.21 \pm 0.01$ & $184.29 \pm 0.01$ & $185.30 \pm 0.02$ & $186.31 \pm 0.02$ \\
\hline 1.00 & $185.02 \pm 0.04$ & $\begin{array}{l}186.02 \pm 0.02 \\
186.4^{\mathrm{a}} \\
186.2^{\mathrm{b}} \\
186.06^{\mathrm{c}} \\
186.46^{\mathrm{d}}\end{array}$ & $186.79 \pm 0.02$ & $187.59 \pm 0.01$ \\
\hline
\end{tabular}

$x_{2}$ is the mole fraction of water in the mixture

\pm is the standard deviation

a Dagade et al. [20]

b Bernal et al. [39]

c Høiland [40]

${ }^{\mathrm{d}}$ Zielenkiewicz et al. [41]

result of this, nonpolar molecules tend to interact among themselves, thereby reducing the number of contacts with water, which results in the superposition of solvation sheaths and the release of water molecules from the solvation shell into the bulk solvent [20]. The outcome of this phenomenon is the dissolution of 15C5 showing a considerable decrease in the value of $V_{\mathrm{m}}^{\circ}$ up to $x_{2} \approx 0.92$. In a water-rich mixture, when $x_{2}>0.92$, one can observe an increase in the standard partial molar volume of $15 \mathrm{C} 5$, which is directly caused by the phenomenon of hydrophobic hydration [39, 40]. Frank and Evans [51] have suggested that water forms cages around nonpolar solutes. The resultant structures are the cause of the formation of new or reinforcement of existing hydrogen bonds between water molecules. The aqueous medium is hostile to organic compounds, isolating them in clathrate-like cavities formed in an energetically favorable, exothermic process consisting in strengthening of hydrogen bonds among water molecules that form the hydration sheath [52]. Forming hydrogen bonds with its other molecules, water causes a geometric distribution of the hydrophobic interactions of organic molecules dissolved in it, causing the hydrophobic hydration to become a factor determining the increase in the $V_{\mathrm{m}}^{\circ}$ values of $15 \mathrm{C} 5$ within this concentration range of mixed solvent. In this process of solvent structure reconstruction, the exothermic enthalpic effect increases at the expense of decrease in entropy (entropy 


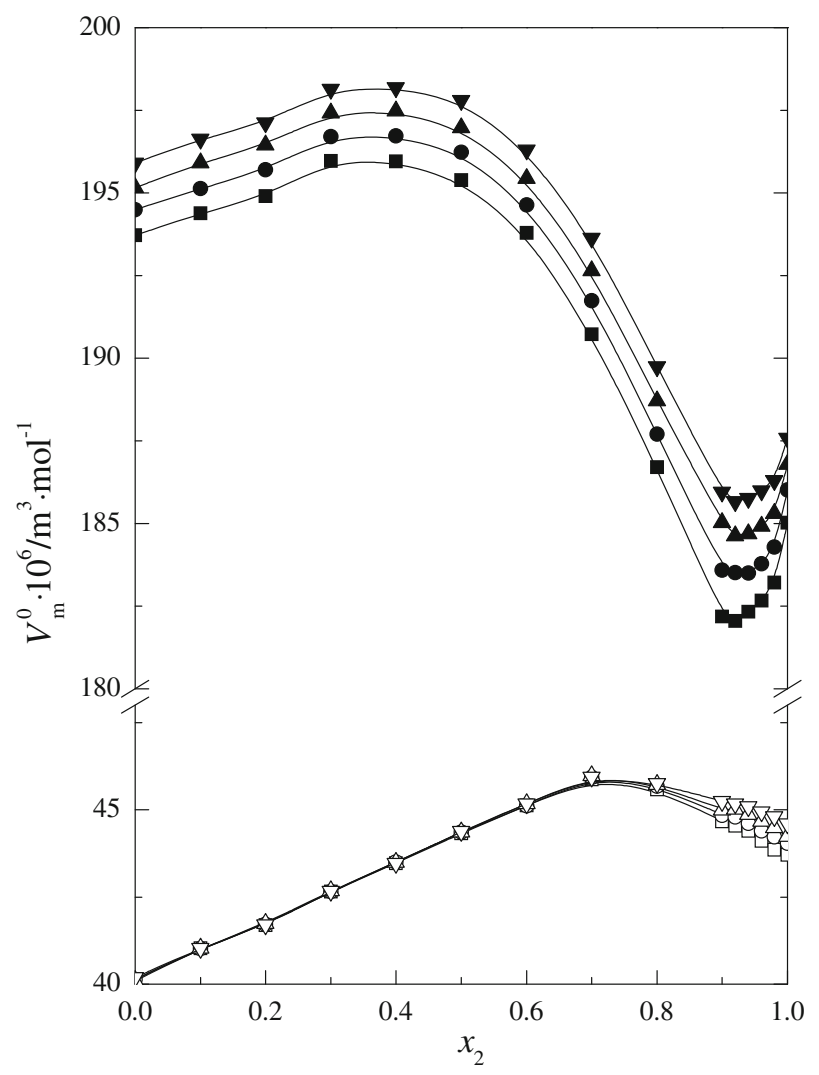

Fig. 1 Standard partial molar volume $\left(V_{\mathrm{m}}^{\circ}\right)$ of 15-crown-5 (full symbol) and urea [21] (open symbol) in the $\mathrm{DMF}+\mathrm{H}_{2} \mathrm{O}$ mixtures for various temperatures: filled square $293.15 \mathrm{~K}$, filled circle $298.15 \mathrm{~K}$, filled triangle $303.15 \mathrm{~K}$, filled tilled triangle $308.15 \mathrm{~K}$ as a function of the mole fraction of water

becomes more negative). Using literature data for the enthalpy of solution and enthalpy of sublimation or evaporation of $15 \mathrm{C} 5$ and urea in the mixtures of DMF $+\mathrm{H}_{2} \mathrm{O}$ [53-56], we calculated the solvation enthalpy $\left(\Delta_{\text {solv }} H^{\circ}\right)$ of these compounds in the solvent mixtures of DMF and $\mathrm{H}_{2} \mathrm{O}$ at $298.15 \mathrm{~K}$. The results are shown in Fig. 2. As is seen, the shape or course of the curve of solvation enthalphy is similar to the course of partial molar volume for $15 \mathrm{C} 5$. The increase of both values within the DMF-rich region $\left(0 \leq x_{2} \approx 0.4\right)$ indicates difficulties in incorporating crown ether molecules into the mixed solvent structure. The increase in the exothermic enthalpic effect, above 0.92 water fraction, as it occurs in the process of crystallization, indicates an increase in the number of hydrogen bonds around the hydrophobic substance $[51,53]$. This is the reason for the increasing values of $V_{\mathrm{m}}^{\circ}$ of $15 \mathrm{C} 5$.

Figure 1 shows a clear effect of temperature on the standard partial molar volumes of $15 \mathrm{C} 5$ within the whole mixture composition range. This value increases with increasing temperature as is expected. The increase in temperature weakens the interactions among molecules, through which the values of the standard partial molar volume of $15 \mathrm{C} 5$ are increased. In the system of DMF $+\mathrm{H}_{2} \mathrm{O}+$ urea, the course of the function $V_{\mathrm{m}}^{\circ}=f\left(x_{2}\right)$ is different. As is seen in Fig. 1, the values of $V_{\mathrm{m}}^{\circ}$ for urea increase with increasing water 


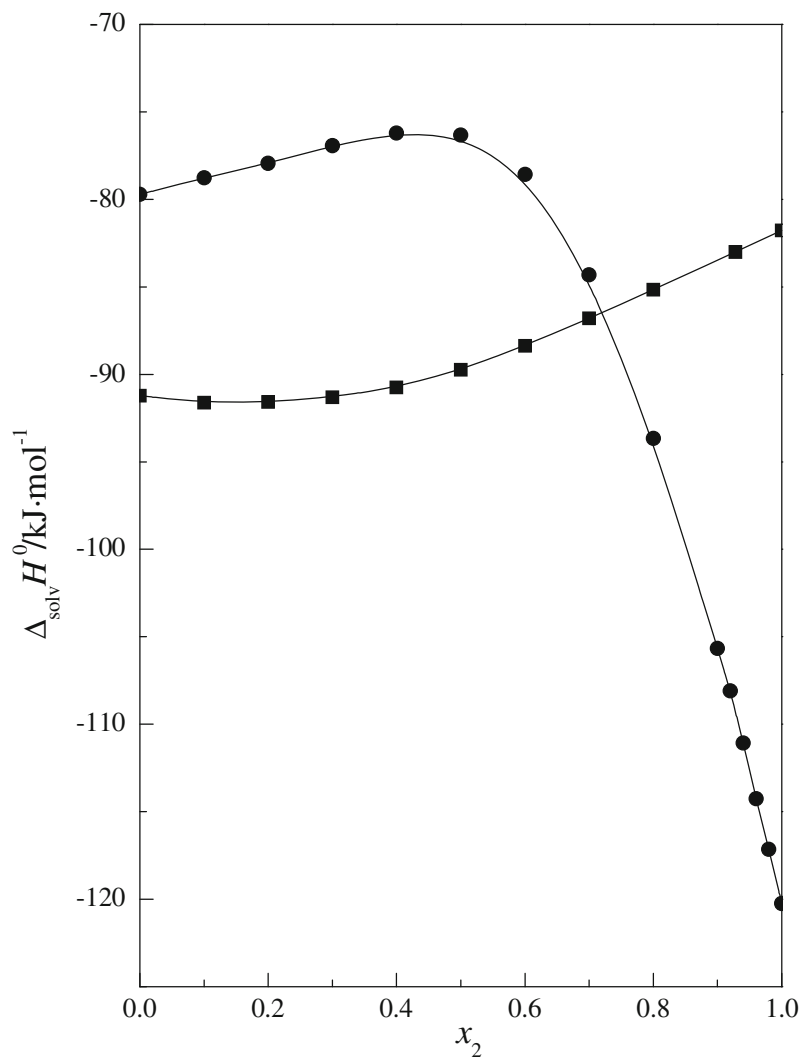

Fig. 2 Standard solvation enthalpy $\left(\Delta_{\text {solv }} H^{\circ}\right)$ (see the text) of: filled circle, 15-crown-5; and filled square, urea in the solvent mixture (DMF $+\mathrm{H}_{2} \mathrm{O}$ ) at $298.15 \mathrm{~K}$ as a function of the mole fraction of water

content up to $x_{2} \approx 0.7$, and then decrease [21]. Only within the area of $x_{2}>0.6$ one can observe changes in the structure of mixed solvent brought about by the presence of urea molecules that form hydrogen bonds with water. Hydrophilic molecules of urea destroy the structure of the mixed solvent, within the water-rich region, which results in a decrease in the value of the standard partial molar volume of urea [21].

The linear temperature dependence of the partial molar volume of $15 \mathrm{C} 5$ allows calculation of the limiting apparent molar expansibilities $(\alpha)$ using Eq. 4:

$$
\alpha=\partial V_{m}^{\circ} / \partial T
$$

The results are presented in Table 5 and Fig. 3. The values of limiting apparent molar expansibilities in water is in good agreement with literature data [57]. For comparison, in the same figure, data for the hydrophile urea are presented. These values were calculated using the data of the partial molar volumes of urea presented in our previous paper [21]. As in other cases, we can observe significant differences in the courses of the functions in the region $x_{2}>0.9$. This reflects the differences in the hydrophobic and hydrophilic properties of molecules of $15 \mathrm{C} 5$ and urea.

In the low and medium water content mixtures no significant changes are observed in the course of the functions $\Delta_{\text {solv }} H^{\circ}=f\left(x_{2}\right), V_{\mathrm{m}}^{\circ}=f\left(x_{2}\right)$ and $\alpha=f\left(x_{2}\right)$ for $15 \mathrm{C} 5$ and urea. 
Table 5 Limiting apparent molar expansibilities of $15 \mathrm{C} 5$ in the DMF $+\mathrm{H}_{2} \mathrm{O}$ mixtures

\begin{tabular}{lll}
\hline$x_{2}$ & $\alpha\left(\mathrm{cm}^{3} \cdot \mathrm{mol}^{-1} \cdot \mathrm{K}^{-1}\right)$ & $R^{2}$ \\
\hline 0.00 & $0.144 \pm 0.003$ & 0.99936 \\
0.10 & $0.150 \pm 0.001$ & 0.99990 \\
0.20 & $0.149 \pm 0.003$ & 0.99870 \\
0.30 & $0.145 \pm 0.001$ & 0.99998 \\
0.40 & $0.149 \pm 0.002$ & 0.99978 \\
0.50 & $0.159 \pm 0.003$ & 0.99942 \\
0.60 & $0.167 \pm 0.002$ & 0.99976 \\
0.70 & $0.193 \pm 0.003$ & 0.99956 \\
0.80 & $0.203 \pm 0.001$ & 0.99994 \\
0.90 & $0.255 \pm 0.017$ & 0.99170 \\
0.92 & $0.239 \pm 0.014$ & 0.99331 \\
0.94 & $0.229 \pm 0.003$ & 0.99960 \\
0.96 & $0.222 \pm 0.001$ & 0.99992 \\
0.98 & $0.206 \pm 0.002$ & 0.99972 \\
1.00 & $0.170 \pm 0.007$ & 0.99628 \\
& $0.18^{\mathrm{a}}$ & \\
\hline
\end{tabular}

$x_{2}$ is the mole fraction of water in the mixture

\pm is the standard deviation

$R$ is the regression coefficient

${ }^{\text {a }}$ Bernal et al. [57]

Worthy of attention is the behavior of those functions in the mixtures with high water content. In this area the courses of all functions for $15 \mathrm{C} 5$ are completely opposite to that which we observed for urea. This is due to the differences in hydrophilic and hyrophobic properties of both investigated compounds. The exothermic process of hydrophobic hydration is the reason for increasing $V_{\mathrm{m}}^{\circ}$ values and decreasing of $\Delta_{\text {solv }} H^{\circ}$ and $\alpha$. In the water-rich region the interaction between the urea molecules weakens, and the interaction between them and water molecules becomes important. Completely reversed behavior of all functions for urea are caused by the destruction of the mixed solvent structure [21].

\section{Conclusion}

The analysis of apparent $\left(V_{\Phi}\right)$ and partial molar volumes $\left(V_{\mathrm{m}}^{\circ}\right)$ of $15 \mathrm{C} 5$ in DMF $+\mathrm{H}_{2} \mathrm{O}$ mixtures made it possible to verify the changes in the mixed solvent structure occurring under the influence of dissolved hydrophobic 15C5. The analysis of the function $V_{\mathrm{m}}^{\circ}=f\left(x_{2}\right)$ for $15 \mathrm{C} 5$ in DMF $+\mathrm{H}_{2} \mathrm{O}$ mixtures gives conclusions that the 15C5 molecules are hydrophobic hydrated at high water content of the mixture. The decreasing values of the virial coefficient $b_{\mathrm{V}}$ with increase of water content in the mixture indicate an increasing effect of hydrophobic hydration of $15 \mathrm{C} 5$ molecules in aqueous medium. The results for hydrophobic 15C5 were compared with analogous results for urea showing hydrophilic properties. The obtained conclusions concerning partial molar volume and expansibility of 15-crown-5 and urea in mixed solvent have been confirmed by the results of the solvation enthalpy of $15 \mathrm{C} 5$ and urea in the mixtures of $\mathrm{DMF}+\mathrm{H}_{2} \mathrm{O}$. 
Fig. 3 Limiting apparent molar expansibilities of filled circle, 15-crown-5, and filled square, urea in the solvent mixture $\left(\mathrm{DMF}+\mathrm{H}_{2} \mathrm{O}\right)$

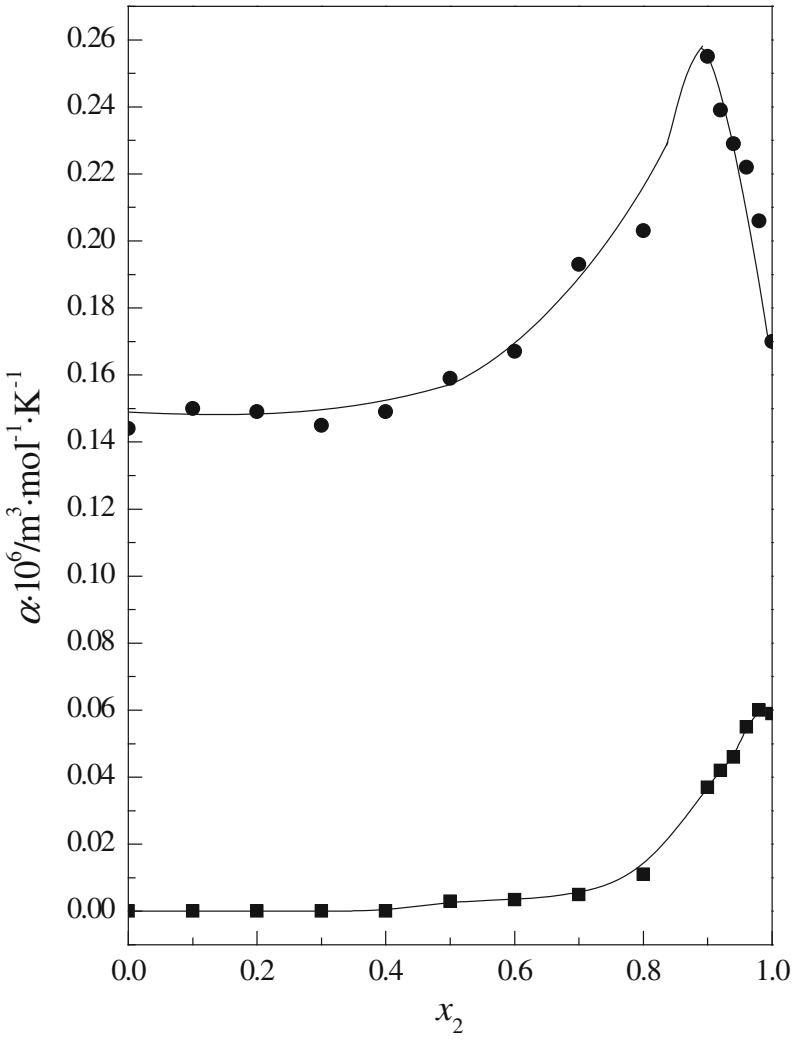

Acknowledgments This study was supported by ZPORR, Project: Post-graduate students-Regional Investment in Young Scientists D-RIM II edition co-financed by the European Union from the European Social Fund within the Operational Program Human Capital (Human-best investment), which is gratefully acknowledged. The authors would like to thank Prof. Adam Bald for discussion and Prof. W. Earle Waghorne for useful suggestions.

Open Access This article is distributed under the terms of the Creative Commons Attribution License which permits any use, distribution, and reproduction in any medium, provided the original author(s) and the source are credited.

\section{References}

1. Illoukhani, H., Khanlarzadeh, K.: Densities, viscosities, and refractive indices for binary and ternary mixtures of $N, N$-dimethylacetamide (1) + 2-methylbutan-2-ol (2) + ethyl acetate (3) at $298.15 \mathrm{~K}$ for the liquid region and at ambient pressure. J. Chem. Eng. Data 51, 1226-1231 (2006)

2. Cwiklinska, A., Kinart, C.M.: Thermodynamic and physicochemical properties of binary mixtures of nitromethane with 2-methoxyethanol + 2-butoxyethanol systems at $T=(293.15,298.15,303.15$, 308.15, and 313.15) K. J. Chem. Thermodyn. 43, 420-429 (2011)

3. Kinart, C.M., Maj, M., Cwiklinska, A., Kinart, W.J.: Densities, viscosities and relative permittivities of some $n$-alkoxyethanols with sulfolane at $T=303.15$ K. J. Mol. Liq. 139, 1-7 (2008)

4. Dubey, G.P., Kumar, K.: Studies of thermophysical properties of binary liquid mixtures of amine and alcohols at various temperatures. J. Chem. Thermodyn. 50, 7-14 (2012) 
5. Chauhan, S., Chaudhary, P., Sharma, K., Kumar, K.K.: Temperature-dependent volumetric and viscometric properties of amino acids in aqueous solutions of an antibiotic drug. Chem. Pap. 67, 1442-1452 (2013)

6. Singh, R., Yasmin, M., Agarwal, H., Shukla, V.K., Gupta, M., Shukla, J.P.: Study of molecular interactions in binary mixtures of formamide with 2-methoxyethanol and 2-ethoxyethanol at varying temperatures. Phys. Chem. Liq. 51, 606-620 (2013)

7. Ghazoyan, H.H., Markarian, S.A.: Densities and thermochemical properties of dimethylsulfone in dimethylsulfoxide and dimethylsulfoxide/water equimolar mixture. J. Mol. Liq. 183, 85-88 (2013)

8. Qi, Z., Soka, M.: Dynamic properties of individual water molecules in a hydrophobic pore lined with acyl chains: a molecular dynamics study. Biophys. Chem. 71, 35-50 (1998)

9. García, B., Alcalde, R., Aparicio, S., Leal, J.M., Matos, J.S.: Solute-solvent interactions in the $(N, N-$ dimethylformamide $+N$-methyloformamide + water) ternary system at $298.15 \mathrm{~K}$. Phys. Chem. Chem. Phys. 3, 2866-2871 (2001)

10. Rouw, A., Somsen, G.: Solvation and hydrophobic hydration of alkyl-substituted ureas and amides in $\mathrm{N}, \mathrm{N}$-dimethylformamide + water mixtures. J. Chem. Soc. Faraday Trans. 1 78, 3397-3408 (1982)

11. Zielkiewicz, J.: Preferential solvation of $N$-methylformamide, $N, N$-dimethylformamide and $N$-methylacetamide by water and alcohols in the binary and ternary mixtures. Phys. Chem. Chem. Phys. 2, 2925-2932 (2000)

12. Gokel, G.W., Leevy, W.M., Weber, M.E.: Crown ethers: sensors for ions and molecular scaffolds for materials and biological models. Chem. Rev. 104, 2723-2750 (2004)

13. Patil, K.J., Dagade, D.H.: Studies of molecular interactions in aqueous and $\mathrm{CCl}_{4}$ solutions involving 18-crown-6 by application of Kirkwood-Buff theory. J. Chem. Thermodyn. 36, 677-682 (2004)

14. Takeda, Y., Tanaka, M., Yamada, H., Katsuta, S.: Stabilities and transfer activity coefficients from water to polar nonaqueous solvents of benzo-15-crown-5- and 15-crown-5-alkali metal ion complexes. J. Coord. Chem. 55, 459-468 (2002)

15. Takeda, Y., Kanazawa, M., Katsuta, S.: Thermodynamic study on transfer from water to polar nonaqueous solvents of 18-crown-6 and its 1:1 complexes with alkali metal ions. Anal. Sci. 16, 929-934 (2000)

16. Patil, J.K., Pawar, R.B., Gokavi, G.S.: Studies of partial molar volumes of 18 -crown-6 in water at $25^{\circ} \mathrm{C}$. J. Mol. Liq. 75, 143-148 (1998)

17. Usacheva, T.R., Kuzmina, I.A., Sharnin, V.A., Chernov, I.V., Matteoli, E.: Influence of the composition of aqueous dimethylsulfoxide solvent on thermodynamics of complexing between 18-crown-6-ether and D,L-alanine. Russ. J. Phys. Chem. A 86, 1064-1067 (2012)

18. Usacheva, T.R., Sharnin, V.A., Matteoli, E.: Effect of solvation on the thermodynamics of the formation of molecular complexes of 18-crown-6 ether with glycine in water-dimethylsulfoxide solutions. Russ. J. Phys. Chem. A 11, 1898-1902 (2011)

19. Rounaghi, G.H., Mohajeri, M., Soruri, F., Kakhki, R.M.: Solvent influence upon complex formation between dibenzo-18-crown-6 with the $\mathrm{Y}^{3+}$ metal cation in pure and binary mixed organic solvents. J. Chem. Eng. Data 56, 2836-2840 (2011)

20. Dagade, D.H., Shetake, P.K., Patil, K.J.: Thermodynamic studies of aqueous and $\mathrm{CCl}_{4}$ solutions of 15-crown-5 at 298.15 K: an application of McMillan-Mayer and Kirkwood-Buff theories of solutions. J. Phys. Chem. B 111, 7610-7619 (2009)

21. Jóźwiak, M., Tyczyńska, M.: Volumetric properties of urea in the mixture of $N, N$-dimethylformamide with water. J. Chem. Eng. Data 57, 2067-2075 (2012)

22. Chan, S.C., Valleau, J.P.: Ultrasonic study of hydrochloric acid association in $N, N$-dimethylformamide. Can. J. Chem. 46, 853-858 (1968)

23. Schmulbach, C.D., Drago, R.S.: Molecular addition compounds of iodine. III. An infrared investigation of the interaction between dimethylacetamide and iodine. J. Am. Chem. Soc. 82, 4484-4487 (1960)

24. Riddick, J.A., Bunger, W.B., Sakano, T.K.: Organic Solvents, Physical Properties and Methods of Purification, 4th edn. Wiley Interscience, New York (1986)

25. Berna-García, J.M., Guzmán-López, A., Cabrales-Torres, A., Estrada-Baltazar, A., Iglesias-Silva, G.A.: Densities and viscosities of ( $N, N$-dimethylformamide + water) at atmospheric pressure from (283.15 to 353.15) K. J. Chem. Eng. Data 53, 1024-1027 (2008)

26. Marchetti, A., Preti, C., Tagilazucchi, M., Tassi, L., Tosi, G.: The N,N-dimethylformamide/ethane-1,2diol solvent system. Density, viscosity, and excess molar volume at various temperature. J. Chem. Eng. Data 36, 360-365 (1991)

27. Sharlin, P., Steinby, K., Domańska, U.: Volumetric properties of binary mixtures of $N, N$-dimethylformamide with water or water- $\mathrm{d}_{2}$ at temperatures from 277.13 to $318.15 \mathrm{~K}$. J. Chem. Thermodyn. 34, 927-957 (2002) 
28. Tôrres, R.B., Marchiore, A.C.M., Volpe, P.L.O.: Volumetric properties of binary mixtures of (water + organic solvents) at temperatures between $T=288.15 \mathrm{~K}$ and $T=303.15 \mathrm{~K}$ at $p=0.1 \mathrm{MPa}$. J. Chem. Thermodyn. 38, 526-541 (2006)

29. Bakshi, M.S., Kaur, G.: Thermodynamic behavior of mixtures. 4. Mixtures of methanol with pyridine and $N, N$-dimethylformamide at $25^{\circ} \mathrm{C}$. J. Chem. Eng. Data 42, 298-300 (1997)

30. Bendová, M., Rehák, K., Matous, J., Novak, J.P.: Liquid-liquid equilibrium and excess enthalpies in binary systems methylcyclohexane + methanol and methylcyclohexane $+N, N$-dimetylformamide. J. Chem. Eng. Data 48, 152-157 (2003)

31. Tong-Chun, B., Jia, Y., Shi-Jun, H.: Excess molar volumes for the ternary mixture $N, N$-dimethylformamide + methanol + water at temperature 298.15 K. J. Chem. Eng. Data 44, 491-496 (1999)

32. Akhtar, S., Faruk, A.N.M.O., Saleh, M.A.: Viscosity of aqueous solutions of formamide, $N$-methylformamide and $N, N$-dimethylformamide. Phys. Chem. Liq. 39, 383-399 (2001)

33. Redlich, O., Meyer, D.M.: The molal volumes of electrolytes. Chem. Rev. 64, 221-227 (1964)

34. de Oliveira, L.H., da Silva, J.M.L., Anzar, J.: Apparent and partial molar volumes at infinite dilution and solid-liquid equilibria of dibenzothiophene + alkane systems. J. Chem. Eng. Data 56, 3955-3962 (2011)

35. Perron, G., Desnoyers, J.E.: Heat capacities and volumes of dilute aqueous solutions of 1,3-dioxane and trioxane. Can. J. Chem. 59, 2599-2600 (1981)

36. de Visser, C., Heuvesland, W.J.M., Donn, L.A., Sosen, G.: Physical chemistry in condensed phases. J. Chem. Soc. Faraday Trans. 1 74, 1159-1169 (1978)

37. Oswal, S.L., Desai, J.S., Ijardar, S.P.: Studies of partial molar volumes of alkylamine in non-electrolyte solvents: I. Alkylamines in hydrocarbons at 303.15 and $313.15 \mathrm{~K}$. Thermochim. Acta 449, 73-89 (2006)

38. Thakur, P.K., Patre, S., Pande, R.: Thermophysical and excess properties of hydroxamic acids in DMSO. J. Chem. Thermodyn. 58, 226-236 (2013)

39. Bernal, P., McCluan, J.: Apparent molar volumes and adiabatic compressibilities of crown ethers and glymes in $\mathrm{H}_{2} \mathrm{O}$ and $\mathrm{D}_{2} \mathrm{O}$ at $25^{\circ} \mathrm{C}$. J. Solution Chem. 30, 119-131 (2001)

40. Høiland, H.: In: Hinz, H.-Ju. (ed.) Thermodynamic Data for Biochemistry and Biotechnology, p. 17. Springer, Berlin (1986)

41. Zielenkiewicz, W., Kulikov, O.V., Kulis-Cwikla, I.: Excess enthalpies and apparent molar volumes of aqueous solutions of crown ethers and cryptand(222) at $25{ }^{\circ} \mathrm{C}$. J. Solution Chem. 22, 963-973 (1993)

42. Sengwa, R.J., Khatri, V., Sankhla, S.: Structure and hydrogen bonding in binary mixtures of $N, N-$ dimethyloformamide with some dipolar and protic solvents by dielectric characterization. Ind. J. Chem. 48, 512-519 (2009)

43. Schmid, E.D., Brodbek, E.: Raman intensity calculations with the CNDO method. Part III: $N, N$-dimethylamide-water complex. Can. J. Chem. 63, 1365-1371 (1985)

44. Eaton, G., Symons, M.C.R., Rastogi, P.P.: Spectroscopic studies of the solvation of amides with N-H groups. Part 1: the carbonyl group. J. Chem. Soc. Faraday Trans. 1 85, 3257-3271 (1989)

45. Eberhardt, E.S., Raines, R.T.: Amide-amide and amide-water hydrogen bonds: implications for protein folding and stability. J. Am. Chem. Soc. 116, 2149-2150 (1994)

46. Pikkarainen, L.: Excess enthalpies of binary solvent mixtures of methanol, ethanol and 1-propanol with formamide, $N$-methylformamide and $N, N$-dimethylformamide. Thermochim. Acta 178, 311-319 (1991)

47. Assarson, P., Erich, F.R.: Properties of amides in aqueous solution. I. Viscosity and density changes of amide-water systems. An analysis of volume deficiencies of mixtures based on molecular size differences (mixing of hard spheres). J. Phys. Chem. 72, 2710-2719 (1968)

48. Dawber, J.G.: Magneto-optical rotation studies of liquid mixtures. Part 5. Binary mixtures of water with dimethylsulphoxide, formamide, methylformamide, dimethylformamide and acetonitrile. J. Chem. Soc. Faraday Trans. 1 78, 1127-1130 (1982)

49. García, B., Alcalde, R., Leal, J.M., Matos, J.S.: Solute-solvent interactions in amide-water mixed solvents. J. Phys. Chem. B 101, 7991-7997 (1997)

50. Geller, B.E.: Svoistva sistemy dimetilformamid-voda. 1. Termokhimicheskiye issledovaniya. Zh. Fiz. Khim. (in Russian) 35, 1105-1113 (1961)

51. Frank, H.S., Evans, M.W.: Free volume and entropy in condensed systems. II. Entropy in binary liquid mixtures; partial molar entropy in dilute solutions; structure and thermodynamics of aqueous electrolytes. J. Chem. Phys. 13, 507-532 (1945)

52. Lipkowski, J.: Hydrphobic hydration. Ecological aspects. J. Therm. Anal. Cal. 83, 523-531 (2006)

53. Jóźwiak, M., Piekarski, H.: Heat of solution of 15-crown-5 ether in the mixtures of water with DMSO, DMF, DMA and HMPA at 298.15 K. J. Mol. Liq. 81, 63-70 (1999)

54. Nichols, G., Orf, J., Reiter, S.M., Chickos, J., Gokel, G.W.: The vaporization enthalpies of some crown and polyethers by correlation gas chromatography. Thermochim. Acta 346, 15-28 (2000) 
55. de Visser, C., Grünbauer, H.J.M., Somsen, G.: Enthalpies of solution of urea in binary mixtures of water and some amides at $25^{\circ} \mathrm{C}$. Z. Phys. Chem. Neue Fol. 97, 69-78 (1975)

56. Della Gatta, G., Badea, E., Jóźwiak, M., Del Vecchio, P.: Thermodynamics of solvation of urea and some monosubstituted $N$-alkylureas in water at 298.15 K. J. Chem. Eng. Data 52, 419-425 (2007)

57. Bernal, P., Bunn, A., Logan, J., McCluan, J.: Apparent molar volumes and adiabatic compressibilities of crown ethers and glymes in aqueous solutions at various temperatures. J. Solution Chem. 29, 651-665 (2000) 